Res Publica. Revista de Historia de las Ideas Políticas ISSN-e: 1989-6115

\title{
El sentido de la natalidad en la fenomenología de la acción política de H. Arendt*
}

\author{
Jorge Brower Beltramin**
}

Recibido: 10 de diciembre de 2017 / Aceptado: 14 de dciembrte de 2018

Resumen. Arendt desarrolla una fenomenología de la acción política sustentada en la experiencia humana dentro de los procesos históricos. En este artículo revisamos algunos de los conceptos centrales de esta propuesta, en particular, el de natalidad, entendido como noción-guía, que permite la apertura del hombre hacia el mundo, a través de la acción concebida por la filósofa como la pura capacidad de comenzar todas las actividades humanas. Del mismo modo observamos la tensión que se genera desde esta propuesta fenomenológica con el lenguaje categorial trascendente de la filosofía, intentando transgredirlo, para finalmente volver a él para dar cuenta de una concepción particular de lo político.

Palabras clave: acción; Arendt; natalidad; política.

\section{[en] The Meaning of Natality in the Phenomenology of Political Action in H. Arendt}

\begin{abstract}
Arendt develops a phenomenology of political action based on human experience within historical processes. In this article we review some of the central concepts of this proposal, in particular, birth, understood as guiding notion, that allows the opening of man to the world, through the action conceived by the philosopher as the pure capacity of begin all human activities. In the same way we observe the tension that is generated from this phenomenological proposal with the transcendent categorial language of philosophy, trying to transgress it, to finally return to it to account for a particular conception of the political
\end{abstract}

Keywords: Action; Arendt; Natality; Politics.

Sumario: 1. Introducción (Algunas señalizaciones contextuales). 2. La natalidad en el centro fenomenológico de la acción política. 3. Implicancias de una transgresión/des-amarre filosófico. 4. Conclusión: desde la acción a la filosofía (nuevamente)

Cómo citar: Brower Beltramin, J. (2019). El sentido de la natalidad en la fenomenología de la acción política de H. Arendt, en Res Publica 22.1, 233-245

\footnotetext{
* Este artículo es parte del desarrollo teórico del proyecto de investigación: La ideología de género como construcción de sentido a propósito de la campaña presidencial de Beatriz Sánchez. Código 031876VM. (20182020). Investigadora responsable, Dra. Alicia Vargas M. Co-Investigador, Dr. Jorge Brower B. Agradecimiento a DICYT, Vicerrectoría de Investigación, Universidad de Santiago de Chile.

** Universidad de Santiago de Chile jorge.brower@usach.cl
} 


\section{Introducción (Algunas señalizaciones contextuales)}

La fenomenología de la acción política de Arendt se vincula a la existencia humana y su posición dentro de ciertas coordenadas históricas. Esta afirmación no hace más que sintetizar de manera sustancial el periplo lleno de incertidumbre experimentado por la filósofa a lo largo de su vida. Hija única de padres judíos rusos, nace en Hanover (Alemania, 14 de octubre de1906), iniciando una suerte de éxodo que la llevará por ciudades como Königsberg, Paris y New York. Esta última la acoge y le permite desarrollar parte de su obra. En Estados Unidos se consagrará como la primera mujer académica en la Universidad de Princeton, construyendo su proyecto teórico sobre lo político a partir de la base formativa entregada por sus maestros alemanes: Husserl, Heidegger y Jaspers. Luego de múltiples avatares biográficos entre los que se cuentan su militancia en la Organización Sionista Alemana, militancia que le costó ser arrestada por la Gestapo en 1933, la relación intelectual y afectiva con su maestro Heidegger y sus postulados respecto al juicio del criminal de guerra nazi Adolf Eichmann ${ }^{1}$, que terminaron en lo que denominó la banalidad del mal, la muerte interrumpe el pensamiento/vida de Arendt el 4 de diciembre de 1975.

De este modo, su vida y la vitalidad de su pensamiento establecen como punto de reflexión/acción inicial la natalidad, acción política primera, encarnación y desplazamiento en y hacia la existencia, que establece de inmediato la distinción del sujeto y la ajenidad, articulando simultáneamente el escenario de la vida social y la vinculación con el otro como modalidad primordial de la acción política. Su reflexión filosófica arranca, de este modo, desde un factum rupturista o fractura que inicialmente aparece como irreconciliable, entre el canon del pensamiento occidental y los traumáticos acontecimientos que dan cuenta de la historia reciente de Europa. La narración de esta historia contiene hechos brutales que desbordan con mucho cualquier nivel de comprensión y respeto por el sentido de la vida humana. Este punto de reflexión/acción se nutre claramente de la ética política puesta en juego en Auschwitz y el resultado de ésta, denominada como ya adelantábamos: la banalidad del mal. Se describe, en este contexto, el mecanismo político de opresión llevado a un extremo, a través de la maquinaria ideológico-tecnológica del exterminio y la consumación de un proyecto totalitario. La extenuante, aniquiladora y larga noche oscura producida por el nazismo sobre Europa, mostró de manera brutal a la filósofa, que el pensamiento está inexorablemente vinculado a los actos, a las acciones del pensador. En esos tiempos de oscuridad, las teorías y

\footnotetext{
Tanto la militancia en la Organización Sionista como su relación con Heidegger y la lectura que realiza respecto al juicio de Eichmann, resultan ser muy significativos para su vida y obra. Efectivamente en 1933 trabaja para una organización sionista vinculada a la persecución de los judíos, utilizando su casa como albergue en el tránsito de los refugiados. En julio de 1933 es detenida durante 8 días por la Gestapo para ser interrogada. Ya hacia fines de 1933, fiel a un pensamiento orientado a la acción, sostiene que debe lucharse activamente contra el régimen nacionalsocialista. Respecto a su relación con Heidegger, esta se sitúa en el contexto de su formación universitaria a partir de 1924 en la Universidad Philipps de Marburg. Allí recibirá clases de prominentes profesores como Heidegger, Hartmann y Bultmann. Su vinculación amorosa con Heidegger termina debido a la afinidad que presentara el filósofo con el PartidoNacional Socialista. Respecto a la postura de Arendt sobre el juicio al criminal de guerra Adolf Eichmann ocurrido en Jerusalén (1961), la filósofa asistió en calidad de reportera para The New Yorker. Su reporte analizaba el trabajo de exterminio efectuado por las SS, denominado banalidad del mal. A juicio de la filósofa se trató de un mal sin maldad, carente de reflexión respecto a lo que ocurría en los campos de concentración nazi. cf. H. Arendt, Eichmann en Jerusalén: un estudio sobre la banalidad del mal, Barcelona, Lumen, 1999.
} 
conceptualizaciones diversas sobre el sentido de la vida humana, son gravemente violentadas y fracturadas por las acciones de exterminio emprendidas desde el dispositivo de poder ideológico nazi. En este espacio vital, Arendt concluye que la vida política tiene su origen en el mundo de la acción inscrita en los procesos históricos.

De este modo, el pensamiento arendtiano no se orienta, como señala Birulés ${ }^{2}$, a retomar los grandes principios y preguntas de la filosofía occidental, sino que genera un proyecto reflexivo que busca organizar políticamente de la mejor manera la sociedad de nuestro tiempo. Esta filosofía política tiene que ver entonces, con pensar en lo que hacemos, en la actividad humana que, en definitiva, constituye nuestra experiencia, cuestión que la intelectualidad en su conjunto no ha considerado o no ha querido considerar. Así, la base o plataforma de este proyecto filosófico nace, en los términos de Birulés ${ }^{3}$, desde la experiencia viva como única referencia válida para orientar dicho proyecto. Se trata de un pensar sin barandilla (Thinking without a bannister) que, en los términos de la filósofa, contiene toda la fragilidad y vulnerabilidad del ser humano. Desde esa sensibilidad, veremos que toda su obra tensiona las categorías del pensamiento respecto de la acción, evitando la ortopedia del ejercicio dialéctico y la tentación de la pura facticidad pragmática. El desafío de este decir filosófico busca un lenguaje esencial, lúcido y sin retoques que pueda hacerse cargo de la vida/experiencia con todos sus temblores, incertidumbres y sueños, en un mundo sobresaltado que, en permanente estado de agonía, intenta reconstruirse y recobrar así cierto orden, aún cuando este sea provisorio.

\section{La natalidad en el centro fenomenológico de la acción política}

Dentro del proyecto filosófico de Arendt, tomaremos ciertos aspectos que nos parecen relevantes para luego desarrollar una metalectura de los mismos, considerando cuestiones fundamentales de la baza fenomenológica que se dejan ver en la intención de la autora. En esa dirección, la fenomenología de la acción política arendtiana se articula desde la acción comprendida como la capacidad esencial de comenzar, fuente que posibilita todas las actividades humanas. Este initium interrumpe y modifica permanentemente los procesos históricos haciendo del hombre un iniciador desde su nacimiento, comprendido como su condición prepolítica. Dentro de este proyecto fenomenológico, lo político es propio de la condición humana y constituye una base performativa que pone en igualdad de condiciones a todos los hombres, más allá de las máquinas de poder que los puedan condicionar. En tal dirección, la biografía propia debe estar guiada por un conocimiento que, como señala Arendt ${ }^{4}$, aspire a la verdad entendida como certeza parcial, que puede ser reemplazada por otras que mejor expliquen ciertos fenómenos de la realidad. En este contexto explicativo, el discurso político, la articulación lingüística de lo político, corresponde a la visibilización última del conato de la existencia entendida como acción, en definitiva como acción política.El énfasis de la fenomenología de Arendt está puesto en situar la

\footnotetext{
F. Birulés, Una herencia sin testamento: Hannah Arendt, Barcelona, Herder, 2007, p. 17.

Ibidem, p. 22.

4 H. Arendt, Vida del espíritu, Barcelona, Paidós, 2002, p. 85.
} 
política como una necesidad ineludible de la vida humana, ya que a través de ella los individuos pueden obtener sus objetivos en paz

La vida política necesita entonces de todas las posibilidades para desarrollarse, más allá de las fronteras del mundo productivo del trabajo y de las normas regulatorias del comportamiento social e individual. La existencia así concebida, no resiste las condicionantes de la productividad y la eficacia que empobrecen y reducen las posibilidades de desarrollo del ser humano. El emprender, el comenzar de la vida política, tensiona los marcos de los protocolos y los manuales de acción empobrecida, para intentar el desarrollo extendido del hombre en el horizonte inabarcable de la existencia, incluyendo de manera fundamental el encuentro con el otro, la aproximación a la ajenidad para el desarrollo de vínculos, de redes vitales para avanzar en la construcción de las sociedades. Este comenzar o archein, entendido como poner en movimiento, afirma Arendt ${ }^{6}$, también corresponde a una forma de gobernar de aquellos que toman la iniciativa en el seno de una estructura social.

Dentro de esta propuesta fenomenológica sobre la acción política, la natalidad ${ }^{7}$ ocupa un lugar central. Esta clave conceptual nos abre a toda posible acción, representa en efecto la posibilidad/capacidad de la acción política. Entendida como hecho prepolítico, Arendt combina para su interpretación las perspectivas agustiniana, kantiana y la que ofrece el judeocristianismo ${ }^{8}$ respecto al acto del nacimiento. Con San Agustín ${ }^{9}$ se instala la concepción de que el hombre es creado como un initium (nuevo comienzo), diferente a la creación del mundo, ya que se trata del comienzo del hombre, enfatiza $A_{r e n d t^{10}}$, que conlleva la creación del principio de libertad. De este modo, el nacimiento está vinculado inseparablemente del anhelo y realización de la libertad. Estas afirmaciones sobre el initium, el nacimiento y la libertad se conectan con la definición de nacimiento aportada por Kant.Para el filósofo de Köninsberg, la libertad en su dimensión trascendental, sin vinculaciones fenomenales, constituye la facultad de comenzar en su condición más pura o esencial. Kant señala que a partir

\footnotetext{
H. Arendt, Qué es política, Barcelona, Paidós, 1997, p. 67.

$6 \quad$ H. Arendt, La condición humana, Barcelona, Paidós, 1993,p. 201

7 En las últimas décadas, los investigadores y lectores críticos de la obra de Arendt han concluido que la categoría de natalidad ocupa un lugar de gran relevancia en el desarrollo del pensamiento arendtiano. Tal es la influencia de este concepto, que incluso se plantea el trabajo de Arendt como una filosofía de la natalidad. Para un desarrollo más extenso de este tópico, cf.; H. Saner, "El significado político de la natalidad en la obra de Hannah Arendt", en Pensando y actuando en el mundo: ensayos críticos sobre la obra de Hannah Arendt. Marco Estrada Saavedra, (comp.). Universidad Autónoma Metropolitana, México D.F, 2003, pp. 19-37 y F. Bárcena, Hannah Arendt: una filosofia de la natalidad, Barcelona, Herder, 2006. p. 36 ss.

8 Como señala Dolan, las referencias al judeocristianismo se pueden observar en el evangelio de Lucas, en donde se señala que el salvador nace en la ciudad de David. Para Dolan, "salvador" se sustituye por "un niño" y "ciudad de David" por "ante nosotros". La salvación del mundo, a través de este nacimiento se realiza en todo momento, se repite con cada nacimiento y en todo lugar. cf. F. Dolan, "An Ambiguous Citation in Hannah Arendts the Human Condition", en The Journal of Politics, Vol.66, N2, 2004, pp. 606-610. Por otro lado, autores como Gottlieb consideran que esta concepción de la natalidad en Arendt da cuenta de una especie de mesianismo judío no apocalíptico que enfatiza el poder del nacimiento como forma de continuidad del mundo. cf.; S.Y., Gottlieb, Regions of Sorrow: Anxiety and Messianism in Hannah arendt and W.H.Auden, Standforf, Standford University Press, 2003.

9 La noción de natalidad está asociada al concepto agustiniano sobre la creación del hombre (initium) según el cual: Initium ergo ut esset, creatuset homo, ante quem nullus fuit (para que hubiera un comienzo fue creado el hombre, antes del cual no había nada). El término natalidad aparece expuesto por primera vez en el ensayo de Arendt titulado: "Understanding and Politics (The Difficulties of Understanding)". El trabajo fue publicado en Partisan Review, XX, 4, julio-agosto, 1953, pp. 377-392.

10 H. Arendt, La condición humana, Barcelona, Paidós, 1993, p.201 ss.
} 
de esa libertad trascendental se establece la dimensión más práctica de la libertad, producida por una voluntad independiente de las diversas coacciones a las que pueda ser sometida ${ }^{11}$.

La tercera perspectiva fundamental utilizada por Arendt para aproximarse a la natalidad, tiene que ver con el aporte de la tradición judeocristiana. Desde esta vertiente del pensamiento religioso, la acción es un milagro que permite innovar en la historia. Un nuevo comienzo es simultáneamente la posibilidad de restaurar la naturaleza de la libertad. En este sentido Arendt ${ }^{12}$ enfatiza en que lo nuevo aparece contradiciendo las leyes estadísticas, es decir, poniendo en riesgo el planteamiento de certezas y en ese sentido aparece en forma de milagro ${ }^{13}$.

Más allá de estas influencias fundamentales, la afirmación que las contiene y las proyecta de manera creativa, tiene que ver con que hemos entrado al mundo por el nacimiento ${ }^{14}$, haciendo de esta afirmación un elemento central para la superación de los totalitarismos, ya que cada nacimiento corresponde a un nuevo comienzo y con ello, la posibilidad de un nuevo mundo ${ }^{15}$. La articulación definitiva de esta fenomenología política de la acción, pondrá el acento en que el hombre debe ser capaz de una acción de lo inesperado realizando lo que es infinitamente improbable. Por tanto, el desarrollo de esta fenomenología implica también la posibilidad que tiene el hombre de interrumpir, modificar y construir procesos históricos. El initium aquí, es un impulso que culmina con acciones llenas de novedad. La natalidad entonces se vincula necesariamente con el concepto de acción. Para Arendt, el recién llegado puede empezar algo nuevo, actuar como la forma de actividad política esencial del hombre. Es en la natalidad y no en la mortalidad, donde se encuentra la base de la categoría central de todo pensamiento político, distinto y distante del pensamiento metafísi$\mathrm{co}^{16}$. De este modo, la reflexión filosófica se vincula directamente con el nacimiento como novedad radical, como milagro que acontece en el seno de lo humano ${ }^{17}$.

Las consideraciones conceptuales que se pueden hacer en torno a la natalidad arendtiana son múltiples. Por de pronto nos permite comprender la libertad política de una nueva forma. Se trata de una libertad que se despliega en la acción misma. En ese horizonte de la acción, la filósofa ubica al discurso señalando que acción y

11 En el contexto de la tercera antinomia de la Crítica a la razón pura, Kant expone su concepción de libertad trascendental, entendida como la absoluta espontaneidad de una causa capaz de generar una serie de estados objetivos por sí misma, sin estar a la vez determinada por alguna otra causa. En esta misma sección desarrolla el concepto de libertad en un sentido práctico, comprendida como la independencia de la voluntad respecto de la imposición de los impulsos de la sensibilidad. La capacidad de comenzar propia de los seres humanos (initium) y así construir procesos históricos planteada por Arendt tiene que ver finalmente con esta libertad práctica kantiana. cf. I. Kant, Crítica de la razón pura, Madrid, Tecnos, 2002.

12 H. Arendt, op. cit., p.201 ss.

13 El trabajo filosófico que va diseñando Arendt se convierte antes que todo en una fenomenología de la vida. Como señala lúcidamente Ricoeur respecto a la motivación profunda de la filosofía, esta tiene que ver con el permanente estado agónico del hombre, en una lucha por la vida que se expresa en un hambre de vivir, en un deseo constante de vivir. cf. P. Ricoeur, La mémoire, l'histoire, l'oubli, Paris, Editions du Seuil, Points Seuil Essais, 2000.

14 H. Arendt, El concepto de amor en San Agustín, Madrid, Ediciones Encuentro, 2001, p.78.

15 H. Arendt, Los orígenes del totalitarismo. Madrid, Taurus, 1998, p. 565.

16 H. Arendt, La condición humana, Barcelona, Paidós, 1993, p. 23.

17 Rosenzweig se refiere a esta novedad radical agregando que dicha novedad es, a su vez, fruto de una generación/fecundación (Gettung/Begattung), anterior al nacimiento. De este modo, el nacimiento se manifiesta como pleno milagro con la fuerza de lo imprevisible y absolutamente nuevo. cf. F. Rosenzweig, La Estrella de la Redención, Salamanca, Sígueme, 1997, p. 89. 
discurso permiten al hombre revelar su personal identidad en el mundo humano. Sin embargo, la aproximación que hace la autora a la natalidad, claramente pone el énfasis, más que en su expresión/reproducción simbólica (discurso), en una valoración de su condición de apertura y de quien nace a partir de esa apertura.Esta condición (la de apertura), que fenomenológicamente puede ser interpretada como desgarro, tensiona y cuestiona al sujeto cartesiano impoluto y desvinculado del conato/agonía existencial. Se trata de una apertura al otro que en su desplazamiento, cuestiona la identidad cartesiana, por el solo acto de la vinculación con la ajenidad y la producción del conflicto con sus diferentes grados de intensidad. Interesa entonces a esta fenomenología desde la natalidad como apertura, los acontecimientos que emergen de ciertas acciones concertadas. Como ya señalábamos al comienzo de este trabajo, los acontecimientos históricos que vivió Arendt, se ven expresados en estas concepciones de lo político a partir de la natalidad. Tanto incide en su propuesta fenomenológica de la acción política su vivencia personal de ciertos hechos (fundamentalmente el nazismo en Alemania), que se distancia de la nominación de filósofa ya que el filosofar en occidente, anestesia el cuerpo y las cuestiones humanas que le son inherentes.

Volviendo sobre algunas derivas semánticas desde el concepto de natalidad, es importante advertir que su despliegue semiótico no se produce en el campo de la biología cíclica, esa en que se produce el embarazo, sino que se fija y extiende desde la singularidad humana que posibilita una condición existencial de la política y que se vincula con el bios politikos que, a través de la acción puede provocar el nacimiento de lo nuevo. Así configurado el mapa conceptual que tiene como nodo de sentido central la natalidad, esta aparece como la condición más general de la existencia humana ${ }^{18}$ Dicha condición se articula sobre la base de dos ejes semánticos centrales. Por un lado en el ámbito de la biología estaría el eje nacimiento/muerte, y por otro, en el ámbito de la política, se produce el de natalidad/mortalidad.

El nacimiento, como señala Collin ${ }^{19}$, es el motivo central en la obra de Arendt, permitiendo un nuevo comienzo, un initium original lleno de posibilidades. La existencia, en tanto que qua humana, es un don que no es necesario explicar. Así, la vida implica la fecundidad en una doble condición de continuidad e inicio haciendo que la natalidad constituya la articulación entre la vida biológica y la vida biográfica, en otras palabras, nos ubica entre lo privado y lo público, conceptualización fundamental del pensamiento arendtiano. De este modo, nacer a la vida, a una vida particular es expresión de la biología, pero también de una biografía cargada de cierta densidad simbólica propia de una fecundidad/otra, narrable y con proyección de futuro. En ese espacio/horizonte, la natalidad expresa una donación, una ética del don. Desde esa ética, lo dado entra en una dinámica que excede al donante y no retorna a él ${ }^{20}$. Lo que se da, constituye una acción fértil cargada de posibilidades en el horizonte del futuro.

Como ya hemos adelantado, la natalidad se constituye en un acto político por su condición de nuevo comienzo y equivale en la metalengua arendtiana a tomar la

18 H. Arendt, H. Arendt, op. cit., p.201 ss.

19 F. Collin, L'Homme est-il devenu superflue? París, Odile Jacob, 1999. pp. 188 ss.

20 Este extremo gesto de generosidad y posibilidad de vinculación no material o supraproductiva, el don, o lo que se da, es en términos de Derrida, aquello que interrumpe la economía y por tanto imposibilita el intercambio, la retribución como resultado. La ética del don tiene que ver de esta forma, con un desprendimiento del donante ante la certeza de no recuperar lo dado u otra cosa equivalente. cf. J. Derrida, Dar (el) Tiempo, Barcelona, Paidós, 1995, p 17. 
iniciativa como cuestión propia de cualquier actividad humana. De esta forma, la filósofa de la natalidad, plantea la posibilidad de referirse a los seres humanos, en la medida que el nacimiento y la muerte estén conectados con el mundo como el gran espacio de aparición. En ese momento se puede establecer una identidad biográfica que se inscribe en la bios de la vida política en relación con los otros y entendida finalmente como elemento protagónico del conatus essendi, de la agonía en la que se desenvuelven los seres humanos en el trance entre el nacimiento y la muerte y entre la natalidad y la mortalidad. De este modo, el conato de la existencia que se traduce en la irrupción y re-construcción permanente de los proceso históricos, tensiona e interpela como Anspruch fundamental, la tradición del pensamiento político, tradición que se instaura en su condición de canon homogeneizador y que por tanto excluye todo lo que no se articule desde la lógica racional dominante, para que dicha tradición se mantenga inalterable frente a las experiencias vitales nuevas contradictorias y conflictivas ${ }^{21}$. Lo político se va a producir de esta forma, a través de la interacción entre los hombres. Para la filósofa, la política se expresa en el -entre- y por tanto trata esencialmente de una relación ${ }^{22}$.

Es en esa dinámica de encuentros y desencuentros que la fenomenología propuesta por Arendt se detiene en el poder de cuestionamiento y de modificación de las representaciones culturales, políticas, de clase, genéricas y legales, entre otros dispositivos de control y disciplinamiento, capaces de desestabilizar los soportes del discurso político dominante. Más allá de la interdicción de la norma, de la máquina de exterminio y del discurso del orden propio de los totalitarismos, está la vida/bios, esa que se desborda y despliega en múltiples espacios y dimensiones. Arendt lo sabe y por eso su proyecto fenomenológico intenta fracturar el horizonte ficticio de la existencia, expresado en estructuras simbólicas, en lenguajes que clausuran más que abren hacia otro horizonte, cuyas fronteras están dadas por el desarrollo de la vida misma, de la experiencia en toda su magnitud, sólo interrumpida por la muerte.

\section{Implicancias de una transgresión/des-amarre filosófico}

Como señalábamos al comienzo de la sección anterior, nuestro interés se concentra en la natalidad como concepto fundamental de la fenomenología aredtiana, para luego, en esta parte del trabajo, distanciarnos de dichos contenidos y así comprender algunas cuestiones esenciales respecto a la intención/perspectiva epistemológica de la filósofa.

Para Abensour, el rechazo de Arendt hacia la filosofía política, se encarna en los filósofos de profesión y en los académicos. El bios theorikos platónico es cuestionado, al igual que la desvalorización de la retórica o doxa cultivada por los sofistas. En este contexto, los filósofos serían los responsables de la desvalorización de la praxis, en una suerte de reduccionismo purista blindado por un logocentrismo clausurante,

${ }_{21}$ Como hemos señalado antes, la obra filosófica de Arendt se vincula directamente a su experiencia de vida. Al respecto, la filósofa se refiere a la llegada al poder del movimiento nacionalsocialista en Alemania como shock de la realidad. Este totalitarismo da cuenta de una horrible novedad, propiciando la dominación total en contra de la libertad humana. cf. H. Arendt, La promesa de la política. Buenos Aires, Paidós, 2015.

22 H. Arendt, Qué es Política, Barcelona, Paidós, 1997. pp.15-28. 
distanciado de la vida concreta ${ }^{23}$. Por el contrario, la propuesta reflexiva y gnoseológica de Arendt vuelve su interés sobre la impureza de la polis y las relaciones por medio de las cuales esta se construye. Así, acontecimientos y conflictos que dan forma al conato de la existencia, exigen la superación de una óptica purista, en pos de una comprensión compleja de la vida política de los seres humanos. Se trata, como señala la filósofa, de la necesidad de concebir la política como acción basada en la pluralidad, en el encuentro dentro de espacios que la propia polis defina desde quienes asumen el recurso de la autoridad ${ }^{24}$. Esta es la intención de su proyecto fenomenológico y simultáneamente constituye su transgresión respecto al discurso filosófico tradicional. El esfuerzo de Arendt tiene que ver entonces, con un desplazamiento epistemológico que va desde las categorías trascendentales de la filosofía, hasta la agonía, la contienda permanente en la que vuelve a comenzar la vida una y mil veces. En ese escenario general, Lefort apunta que Arendt comienza a pensar políticamente con la llegada del nazismo a Alemania en $1933^{25}$. La propia intelectual dirá que el día del incendio del Reichtag (27 de febrero de 1933), nace como pensadora política ${ }^{26}$. Como consecuencia de esta postura vital, el trabajo reflexivo y analítico emprendido apunta a un des-amarre respecto a la filosofía tradicional, fundada sobre un logos ontometafísisco, desvinculado de la vida/bios y de la rica experiencia de vivir. Esta posición la acerca más a la concepción del lenguaje (Sprache) de Heidegger en relación al Dasein (estar ahí) ${ }^{27}$. A través de la célebre afirmación: Die Spracheist das Haus des Seins (el lenguaje es la casa del ser), el filósofo nos dice que el lenguaje es la morada del ser, es decir, expresión de su existencia humana. En dicho sentido y con este estatus epistemológico, Arendt adscribe esta concepción del lenguaje, entendido como manifestación de la experiencia, alejándose definitivamente de lo que Steiner denomina posición logocrática trascendentalista ${ }^{28}$, que se postula por

23 M. Abensour, Hannah Arendt contre la philosophie politique? Sens \& Tonka éditeurs, 2006. pp 60 ss.

24 En sintonía con esta concepción de política, Revault d'Allonnes hace referencia a la Edad Media, período en que la autoridad era expresión de emancipación y poder. En tal sentido, se vincula con la comprensión de la autoridad como una forma de poder inaugural o poder de los comienzos que, en el contexto arendtiano, se instaura en cada initium o inicio de los proyectos políticos. cf. M. Revault d'Allonnes, El poder de los comienzos: ensayo sobre la autoridad. Madrid, Amorrortu, 2008.

25 C. Lefort, "Hannah Arendt y la cuestión de lo político", en F. Birulés, (Compiladora). Hannah Arendt: el orgullo de pensar, Barcelona, Gedisa, 2000, pp. 131-144.

26 La noche del 27 de febrero de 1933 el joven izquierdista holandés Marinus van der Lubbe incendió el parlamento alemán. Sin existir certeza absoluta sobre quién o quienes le mandataron esta acción, el atentado sirvió como pretexto para suprimir derechos constitucionales, perseguir a miles de opositores e imponer un régimen totalitario. Adolf Hitler había sido nombrado canciller de Alemania el 30 de enero de 1933. Esa misma noche, Hitler culpó a los comunistas del incendio. Al día siguiente logró que Hindenburg firmara un decreto de Protección del Pueblo y del Estado, suspendiendo el derecho de reunión y la libertad de expresión entre otras garantías constitucionales. Se ponía en marcha de esta forma el régimen totalitario nazi. La democracia de la República de Weimar no había sobrevivido ni un mes desde el nombramiento de Hitler como canciller. Este trágico acontecimiento para la vida política de Alemania tuvo un gran impacto en Arendt y tal como señala la filósofa, puede considerarse un hito fundamental para la articulación de su fenomenología de la acción política. Para una revisión exhaustiva de este hecho cf. G. Dimitrov, El Incendio del Reichstag, México, Grijalbo, 1968.

27 M. Heidegger, Ser y Tiempo. Madrid, Trotta, 2009. p.163 ss.

28 En la perspectiva de Steiner es necesario agregar que esta concepción logocrática del lenguaje está asociada a una lingüística trascendente que postula un origen del lenguaje anterior y exterior a la evolución humana en un sentido secular y naturalista. Steiner señala finalmente que dicho origen es teológico. Esta condición teológica de la perspectiva logocrática implica que la revelación del ser en el logos, como manifestación de Dios, es antes que todo autoritaria y por tanto, cargada de imperativos esenciales para el hombre. cf. G. Steiner, Los logócratas. México. F.C.E. Siruela. 2007, pp. 13-20. 
encima del tráfago de la vida ${ }^{29}$. Será entonces el lenguaje vinculado a la existencia y su construcción y re-construcción permanente, el instrumento comunicativo que mejor sirve a la fenomenología de la acción política, lenguaje que de todas formas se hace cargo incompletamente del temblor de un exceso permanente, el exceso de la vida/bios, de la vida en sí, resistente y desbordante en relación a procesos dialécticos y de síntesis reduccionistas que no logran atrapar/contener su multiplicidad.

El exceso de la vida/bios al que nos referíamos, se despliega desde el planteamiento de la natalidad hecho por Arendt, instalando el punto de inflexión que señala un camino distinto y distante respecto de la comprensión teórica de la vida y de las relaciones entre los seres humanos por medio de las cuales se generan y desarrollan los procesos históricos. Como hemos expuesto antes, la natalidad-concepto/guíaen la obra de la filósofa, es la que nos abre a la vida, a ese temblor permanente al que nos referíamos, hambre de vivir o deseo de vivir en donde el initium arendtiano representa una aventura abierta, cuyo espacio de exploración se encuentra en un permanente estado de construcción. En esta dirección, el methaphorikos del lenguaje filosófico se fragmenta y es desbordado desde la exigencia fenomenológica desarrollada por Arendt, haciendo que la posición analítica logocéntrica, proyectada en un juego semiótico/hermenéutico propio del methaporikos de la filosofía, se vuelva sobre la densidad semántica generada en ese juego, generando una dinámica en la que el sentido se debate y desenvuelve en los infinitos pliegues del lenguaje, sin avanzar más allá del horizonte simbólico construido por el propio lenguaje.

De este modo, la fenomenología de la acción política de Arendt intenta, desde su base epistemológica, transgredir en todo momento el logos finalmente reduccionista de la filosofía, apostando por una fractura final que pueda suspender/detener la invaginación escritural que padece desde sus orígenes. Como hemos señalado de diversas formas en este trabajo y a propósito de la natalidad, el foco de interés se vuelca sobre la experiencia del conatus essendi, más allá del acto de nombrar, obligando a la reflexión analítica a vincularse decididamente con el mundo, a través del haz de relaciones o interacciones entre los seres humanos como protagonistas de los procesos históricos. Luego de la última dislocación del lenguaje teórico, o tal vez habría que decir, antes de toda producción discursiva teórica, emergen los acontecimientos, la vida política de los hombres, condicionada por las máquinas de poder y los dispositivos ideológicos que las regulan y comandan. More metaphoriko, más allá de la construcción simbólica del mundo, se revela el hombre como cuerpo que subordina al logos, mostrando su spaltung (herida), silenciando toda lalia, para concentrarse en el tránsito entre la vida y la muerte y en las condiciones en que se da dicho viaje. En ese trayecto, Aushwitz aparece como topoi de muerte, como espacio de exterminio, vinculando simbólicamente el nombre de Aushwitz a ese espacio de exterminio, provocando la necesidad de regreso a dicho espacio, mundo de la experiencia en que se aniquila la vida desprovista de cualquier identidad ${ }^{30}$. Sin duda, esta instancia

29 Dentro del nutrido diálogo filosófico entre Arendt y Heidegger, efectivamente podemos plantear un acercamiento de sus respectivas concepciones del lenguaje. Sin embargo, en lo medular, la filosofía de la natalidad arendtiana revierte el valor de la muerte planteado por Heidegger. Para el filósofo, la muerte constituye un elemento primordial que condiciona toda la existencia humana. Arendt en cambio, considera la natalidad por sobre la mortalidad. Es la natalidad, la categoría central de lo político, entendida como capacidad de irrumpir y comenzar o como el milagro que salva al mundo.

30 Los campos de concentración nazis son la expresión técnica de la solución final respecto a los judíos, solución que supera el estatus jurídico del crimen para poner en práctica la conditio inhumana más extrema y absoluta. 
llena de dolor, motiva en la filósofa el desarrollo de su concepción de lo político, que puede ser entendido también como una provocación a vivir la experiencia de la integración de los cuerpos, de su proximidad y capacidad de acción. En términos de la fenomenología de Levinas, esta provocación a vivir puede ser entendida como la exigencia de hacerse cargo del otro, de su humanidad vulnerable ${ }^{31}$. Efectivamente, en el trayecto filosófico levinasiano, al igual que la propuesta de Arendt, representa una incitación al mundo de la experiencia, en donde la presencia de los cuerpos resulta insoslayable, vinculada fuertemente a la acción. Así, la expresión de lo político y su funcionamiento, desplaza los sistemas simbólicos, re-direccionando permanentemente esa acción al mundo de la experiencia, evitando la tentación del discurso estructurante, de la norma preestablecida, absolutamente ortopédica respecto al conato vital de la existencia. En efecto, más allá de la palabra de orden, de su estrechez y restricción, los seres humanos comienzan una y otra vez, proyectos para sus vidas, en los cuales el otro resulta ser una ajenidad necesaria como posible interacción. Así, la propuesta de Arendt gira desde la teoría, que exhibe muchos pliegues de sentido carentes de experiencia, hacia los seres humanos dispuestos a encontrarse y por tanto a comenzar diversos procesos vitales. En esa instancia se producirá un cara a cara que hace de la vida un encuentro y por tanto una posibilidad de comunión, de acuerdo para pensar juntos el mundo. Desde el imperio de la experiencia se dará un valor nuevo al logos-otro que expresa en forma genuina el acontecer del mundo, liberado del lenguaje ordenador y situado como señala Wittgenstein en lo más concreto ${ }^{32}$, para intentar capturar el puro acto de vivir o tal vez debiéramos decir, el puro acto político de vivir, recogiendo las circunstancias cotidianas de la vida humana. El interés de Arendt por el lenguaje, corresponde a lo que Levinas denomina ámbito del decir ${ }^{33}$ entendido como lenguaje que se estructura sobre una vocación descriptora del cara a cara, de la experiencia más-allá-del-ser, hacia el incontenible flujo de la existencia que, como hemos señalado en otro trabajo ${ }^{34}$, no acepta el eco de la voz metafísica, exigiendo la instauración de una palabra vinculante entre los hombres ${ }^{35}$. La extrema gravedad de la fenomenología arendtiana radica precisamente en la necesidad final de comprender la existencia con toda su complejidad en su dimensión de conato, de combate cuyo horizonte sólo limita con la muerte.

Se trata entonces de una fenomenología de la acción política que delimita su capacidad gnoseológica desde la existencia, que no acepta la generalización teórica y la reflexión desvinculada de la vida concreta. Fenomenología de lo concreto que se hace cargo de esa vida en su dimensión de subjetividad vinculada al mundo mo-

Estos espacios de confinación, tortura y muerte representan la manifestación delirante de la dominación total y del exterminio en el doble sentido de la muerte física y de la muerte de la memoria hasta su más profunda huella simbólica. cf. G. Agamben, Homo Sacer I. El poder soberano y la nuda vida. Valencia, Pre-textos, 1998, p. 211.

31 E. Levinas, De otro modo que ser, o más allá de la esencia. Salamanca, Ediciones Sígueme, 1987, pp. 45-68.

32 L. Wittgenstein, Investigaciones Filosóficas. Barcelona, Ediciones Altaya S.A. 1999, p.41-42.

33 E. Levinas, op. cit., pp. 48-50.

34 J. Brower, "Deconstrucción del Otro Hombre: hacia una manifestación de Dios más allá del sistema de significación ontometafísico", en Revista Escritos y Pensamiento Humanista. Vol.18. º40, 2010 pp.14-35.

35 Esta comprensión/valoración del lenguaje, también la hemos hecho a partir de la obra de Levinas. El ámbito del decir se contrapone al de lo dicho, entendido como el de una sedimentación lingüística que vemos en los diccionarios y en los lenguajes categoriales y definicionales en general. La filosofía estaría construida básicamente sobre lo Dicho y por tanto proyectos fenomenológicos como los de Levinas y Arendt intentar alimentar y enriquecer ese lenguaje desde el mundo de la experiencia y la acción. Cf. E. Levinas, op. cit., pp.69-116. 
derno, des-amarrada de cualquier esencialismo ${ }^{36}$. La proyección del hombre desde la natalidad lo sitúa -para con el otro- sin opciones, sin alternativas, para construir relaciones y comunidad dentro de procesos sociales e históricos. Se trata en otros términos, de un desplazamiento hacia el prójimo en un espacio de proximidad y de contacto más allá de la geografía borrosa de cualquier lenguaje simbólico. Allí se juega la transgresión epistémica de Arendt y su esfuerzo por delinear una filosofía política desde la experiencia, transgresión epistémica que se distancia de la teoría en su condición de discurso espurio y esencialista. La mirada se vuelca hacia la vida y en ella se detiene en el hombre agónico que ligado a otros hombres, establece formas de vida más participativa y comunitaria. En este punto descansa la propuesta de Arendt, en una acción política para la paz, en donde lo humano emerge con todo su valor de vulnerabilidad exigiendo la expresión de los cuerpos, suspendiendo todo discurso, para concentrarse en el conato de la existencia y así producir nuevos horizontes de vida, nuevos comienzos y esperanzas. En ese trance, la muerte simbólica es una expresión innecesaria, un esfuerzo retórico descartable ante la inmensidad de la vida que sólo será interrumpida por la muerte-otra, esa que silencia la voz e interrumpe la aventura vital por un instante para volver a comenzarla.

\section{Conclusión: desde la acción a la filosofía (nuevamente)}

Hannah Arendt vivió en tiempos difíciles, qué duda cabe de ello. Su condición de judía en la Alemania nazi volvió aún más dramática su existencia, pero al mismo tiempo le permitió elaborar una fenomenología de la acción política cuya densidad conceptual hunde sus raíces en la experiencia. De este modo, la vida política a la que apunta la filósofa, emerge del conato en el que se desenvuelve la existencia modelando a su vez los procesos históricos en los que el ser humano es el principal protagonista. El shock de la realidad que ella misma señala haber sufrido en carne propia, moviliza todo su aparato reflexivo hacia la experiencia y la posibilidad de generar espacios para la vida en paz. Desde ese transitar por la existencia, cargado de vulnerabilidad, pero también de deseos por construir proyectos vitales, los seres humanos irrumpen en el mundo y a través de esa acción, Arendt plantea un concepto central dentro de su propuesta fenomenológica; la natalidad. Como hemos señalado, este concepto representa la posibilidad/capacidad de toda acción política. Si bien la filósofa utiliza como plataforma teórica las aportaciones de San Agustín, Kant y la tradición judeocristiana, su intención comprensiva vuelve la mirada sobre el mundo de la acción con toda su impredecibilidad e incerteza. El delirio ideológico generado por el nacionalsocialismo en Alemania y sus consecuencias destructivas en buena

36 Es interesante consignar que para Arendt, el mundo moderno se caracteriza por la dimensión política que da sentido y organiza los acontecimientos que le dan forma. Es el caso de la producción científica, leída y entendida desde la lectura política. La utilización del átomo con fines destructivos es un ejemplo de esto. Para la filósofa el lanzamiento de la bomba atómica será el hito que marca el comienzo del mundo moderno. El protagonismo del homo faber en este mundo, convierte a este último en un espacio de comportamiento productivo. Para Arendt, la verdadera acción política debe superar el imperativo de la utilidad, regulada por una tecnociencia que instrumentaliza todo. El poder de esta instrumentalización de la vida reduce la acción política a una mera gestión administrativa. Cf. É. Tassin, Le trésor perdu. Hannah Arendt l'intelligence de l'action politique, París, Payot, 1999 y D. Villa, Arendt and Heidegger: the Fate of the Political. Princeton, Princeton University Press, 1996. pp. 189 y ss. 
parte del mundo inspirarán la reacción filosófica de Arendt, pero también de otros filósofos que compartieron ese contexto histórico. En dicho escenario, el initium aredtiano importa claramente, más allá de su conceptualización, como un conjunto de acciones probables y novedosas. Se trata, de este modo, de una fenomenología de la acción política que construye una lente epistemológica para abrir un espacio a la natalidad entendida como apertura de un sujeto que nace amarrado a la existencia desde su propio cuerpo. Nos queda claro, desde el inicio de los planteamientos de Arendt, su intención y necesidad de alimentar la propuesta fenomenológica desde la experiencia evitando el trascendentalismo de las categorías propias de la filosofía. La comprensión de la acción política justamente se debate entre la contienda propia de estar vivos en una comunidad humana y la expresión discursiva de esa contienda articulada sobre un logos-otro que rechaza el trascendentalismo ontometafísico, pero que a la vez exige expresarse a través de núcleos de sentido amarrados a lo concreto. En esta dirección se va generando lo que denominamos trasgresión o des-amarre filosófico, acciones ambas sustentadas sobre un cuestionamiento radical al bios theorikos de la tradición platónica, abriendo posibilidades múltiples de conocimiento y comprensión del comportamiento humano, situadas en la impureza de la polis. Es en ese topoi/espacio, donde se puede pensar y conceptualizar la política como acción, teniendo como fondo un horizonte plural de identidades e interrelaciones. La fenomenología de lo político planteada por Arendt, siempre gira en torno a ese espacio y el lenguaje que lo describe sin mayores pretensiones retóricas, cercano muchas veces a la doxa común, resulta incompleto en su intento explicativo y siempre desbordado por la vida/bios que busca expresarse más allá de la logocracia a través de la cual se articula el pensamiento contemporáneo. El pensamiento de Arendt intenta superar precisamente ese edificio conceptual/abstracto, para comprender la vida en términos dinámicos, desplegada en vectores performativos, en acciones y movimientos que le van dando sentido, siempre incompleto en busca de verdades más ciertas y estables. En ese espacio, esta filosofía política de la acción se enfrenta y convive con la tragedia humana expresada en Auschwitz, como una tecnología novísima del totalitarismo capaz de un exterminio que pulveriza los principios fundamentales del humanismo occidental. La libertad, igualdad y fraternidad, como apunta Agamben, no sobreviven para el planteamiento de una Ética more Auschwitz demonstrata ${ }^{37}$.

En ese esfuerzo, la fenomenología de la acción política de Arendt intenta una fractura final respecto al lenguaje filosófico, fractura/apertura, luego de la cual emerge epifánica la figura del hombre en acción y constructor de los procesos históricos. Sin embargo, ese more metaphoriko o más allá de la construcción simbólica del mundo, sólo puede ser contenido-a duras penas- por la discursividad reflexiva y analítica de la filosofía. Como nos aporta Derrida ${ }^{38}$, siempre volvemos a la palabra, al logos como una forma insoslayable de reiniciar el esfuerzo expresivo respecto a la obsesiva orientación al otro. En tal dirección, la voz de Arendt recoge la multiplicidad de voces que le aporta la tradición filosófica dándoles vigor y una densidad

37 Se puede plantear que la puesta en marcha de estas máquinas de exterminio (Auschwitz entre ellas), conducen a un desencanto y decepción que se proyecta a horizontes de futuro incierto. Sin embargo, aprender de la decepción también nos abre a la posibilidad de corregir nuestras vidas, a renacer asegurando en ese camino un referente ético más robusto y consolidado. Cf. G. Agamben, Homo Sacer III. Lo que queda de Auschwitz: el archivo y el testigo. Valencia, Pre-textos. 2000. p.10 y ss.

38 Cf. J. Derrida, La desconstrucción en las fronteras de la filosofia: la retirada de la metáfora, Barcelona, Paidós, 1989. 
semántica diferente. Como hemos señalado en el trabajo, la apuesta epistemológica de la filósofa se encamina desde el comienzo a tensionar el marco conceptual de la filosofía, llevándola a fronteras, más allá de las cuales se encuentra el conatus essendi y su contienda permanente. Precisamente esta contienda que no acepta la explicación genérica/universal, es la que le reclama y exige a Arendt desandar de alguna manera el camino de la transgresión o como hemos dicho, del des-amarre filosófico, para volver a hablar con una voz nueva que, nutriéndose de voces antiguas, ponga luz sobre un tópico central en la vida de los seres humanos; su acción política entendida como apertura al mundo para volver a comenzar la vertiginosa empresa de vivir solos y con los otros en la incerteza del devenir, con la ilusión de construir sociedades que puedan desarrollar sus proyectos de sociedad en paz, regulados y regidos por constituciones que garanticen la libertad del ciudadano en contextos de Estados soberanos, a partir de los cuales sea posible resemantizar el sentido de la paz, después de la Segunda Guerra Mundial, asumiendo desde esa experiencia devastadora, una concepción jurídica y política en que se enfaticen la responsabilidad para con el otro, cuyo valor central es el respeto por la vida ${ }^{39}$.

39 La concepción de paz desarrollada en Arendt se conecta con los planteamientos que hace Kant sobre este tópico. La vinculación específica se refiere en primer término a su exploración semántica (qué entendemos por paz) ligada al contexto o época histórica en que se desarrolla y expresa. A partir de esta base, el énfasis de Arendt es puesto en la necesidad de constituciones robustas que garanticen las libertades individuales y que puedan desarrollarse en Estados soberanos. Cf. H. Arendt, Conferencias sobre filosofia politica en Kant, Buenos Aires, Paidós, 2009, p. 212. 